\title{
Linguistic Diversity, Pluralism and National Development in Africa
}

\author{
Beban Sammy Chumbow*
}

\begin{abstract}
In the quest for national development in Africa, how are the facts of linguistic diversity to be reconciled with pluralism, the African Union's ideological option for nation building? From the perspective of language planning theory, we motivate, justify, rationalise and propose a tier stratification model of language planning predicated on an adaptation of Jurgen Habermas's 1965 notion of the public sphere. Concretely, the bifurcation of the public sphere into the public and private domains and a principled stratification of languages of the nation-state into these domains, leads to a rational planning process. The process is characterised by the maintenance and consolidation of the linguistic and cultural identities of ethno linguistic communities at the microplanning level while constructing a pluralistic national identity at the macro-planning level. The efficacy of the interaction between the two domains is mediated by two principles. The Principle of Functional Complementarities (PFC) requires that all languages be assigned (by the state) some valorising functions, i.e. functions that procure economic, social, and political advantages, thereby contributing to elevating the status of the ethno-linguistic communities. The Principle of Attitude Engineering (PAE) is expected to effect a positive change of attitude, culminating in a change of mindset congruent with the paradigm shift of national development anchored on pluralism. This model of Language Planning ensures the empowerment of linguistic minorities, provides for a reduction of ethno linguistic dominance and ipso facto, ensures the democratisation of access to knowledge, especially developmentrelevant knowledge for the national development enterprise.
\end{abstract}

* University of Yaounde 1, Cameroon. E-mail: sammybchumbow@yahoo.fr. 


\section{Résumé}

Dans la quête du développement national en Afrique, comment les faits de la diversité linguistique doivent-ils se réconcilier avec le pluralisme, l'option idéologique de l’Union africaine pour l'édification de la nation? Du point de vue de la théorie de la planification linguistique, nous motivons, justifions, rationalisons et proposons un modèle de la planification linguistique fondé sur une adaptation de la notion de sphère publique de Jürgen Habermas (1965). Concrètement, la bifurcation de la sphère publique vers les domaines publics et privés ainsi que la stratification fondée sur des principes des langues de l’État-nation dans ces domaines, conduit à un processus de planification rationnelle. Le processus est caractérisé par le maintien et la consolidation des identités linguistiques et culturelles des communautés ethnolinguistiques au niveau de la micro-planification, tout en construisant une identité nationale pluraliste au niveau de la macro-planification. L'efficacité de l'interaction entre les deux domaines sont dictées par deux principes. Le principe des complémentarités fonctionnelles (PFC), requiert que certaines fonctions valorisantes soient attribuées (par l'Etat) à toutes les langues, c'est-à-dire les fonctions qui procurent les avantages économiques, sociales et politiques, contribuant ainsi à élever le statut des communautés ethnolinguistiques. Le principe dit " Principle of Attitude Engineering » (PAE) devrait avoir comme effet un changement positif d'attitude, aboutissant à un changement de mentalité en harmonie avec le changement de paradigme en matière de développement national ancré sur le pluralisme. Ce modèle de planification linguistique assure le renforcement des minorités linguistiques, envisage une réduction de la domination ethnolinguistique et, ipso facto, assure la démocratisation de l'accès à la connaissance, en particulier les connaissances pertinentes en matière de développement pour l’initiative de développement national.

\section{Introduction}

From the linguistic perspective, the single most important characteristic of African nations is linguistic diversity. All African countries are, indeed, multilingual and multicultural in varying degrees. This fact establishes the existence of a multiplicity of ethno-linguistic communities within each nationstate. Each linguistic community is in turn characterised by an autonomous ethno-linguistic identity. On the other hand, the most heralded paradigm of development in the current state of African nationalism is predicated on the ideal of pluralism as an ideological foundation of nationhood in Africa. In the quest for national development in Africa, how are the facts of linguistic diversity and the existence of ethno-linguistic identities to be reconciled with the exigencies of pluralism?

Put simply, how do emergent African nations achieve unity in diversity? 
This work undertakes the challenge of providing a framework for maintaining and consolidating the linguistic and cultural identity of linguistic communities at a micro-linguistic planning level while constructing a pluralistic national identity at the macro-linguistic planning level. From the perspective of language in the public sphere, solving this national equation requires mediating between languages of the private domain and languages of the public domain. This is accomplished through the agency of a model of tier stratification of languages of the nation in consonance with the instrumentation of principles of functional complementarities and attitude engineering to be motivated and discussed.

\section{National Development}

National development is a much sought-after ideal in the developing nations of Africa as evidenced by the well known periodic (Five or Seven-Year) National Development Plans characteristic of these countries. Yet, despite over half a century of planning for development, it cannot be said that the ideal of development, (the object of the search), has been achieved. In spite of evidence of growth, the quintessence of development has eluded all efforts and initiatives as well as all economic paradigms designed for development in Africa, from the Structural Adjustment Programme (SAP) to the New Partnership for African Development (NEPAD). The relative achievements of African nations since independence in relation to the contrasting evidence of extensive abject mass rural poverty, is best described as growth without development. This sorry state of affairs is due, in part at least, to the fact that the language factor in development has not been fully and comprehensively addressed or has been addressed only haphazardly and half- heartedly (Chumbow 2005).

It has been argued forcefully that the economic and social development of Africa depends crucially on the development and use of African languages in the enterprise of national development (Bamgbose 1991 and 2003; Chumbow 1990 and 2005-among others). Thus, Chumbow (2005:168) articulates this issue in the following terms:

An evaluation of the efforts of African countries in the enterprise of national development shows that in most cases, there has been what we may call growth without development because despite visible signs of economic progress (along with considerable population explosion), African countries are characterised by a massive presence of abject poverty in the rural communities (villages) and the outskirts of urban areas (where most city dwellers live) surrounding a few affluent villas capped by token sky-scrapers in the city centres. 
While there is no universally acceptable and accepted definition for national development, a situation where evidence of conspicuous consumption in parts of the urban centres contrasts sharply with the generalised poverty, misery, illiteracy, ignorance and disease in most of the national territory is far from being a reasonable approximation of the national development ideal. The target of development should be the improvement of the welfare and social well-being of the entire citizenry.

We define national development (in Chumbow 1990) as 'the nation's human resources acting on its natural resources to produce goods (tangible and intangible) in order to improve the welfare and social well-being of citizens of the entire nation in terms of indicators of development predicated on minimum standards of living which include (among others) a reasonable standard of good health and housing facilities, food security, life expectancy (reduction of infant mortality and improvement of maternal and reproductive health), education and literacy, and employment.

\section{Language, Education and Development}

The medium of education in most of Africa is still largely via an exoglossic or foreign language of colonial heritage such as English, French, Portuguese, Spanish, etc., with the consequence that only an estimated 20 to 40 percent of the African population is educated in these languages. The fact that the sum total of the knowledge, technology, skills and techniques relevant to and required for national development are confined to and transmitted in a foreign language used by a relatively small fraction of the population means that the majority (60 to 80 percent) who do not speak the official foreign language are literally marginalised and excluded from the development equation.

This has led to the widely held position of language experts over the years (since UNESCO 1953) adopted by the Organization of African Unity (OAU 1986) and consolidated by the African Union (AU 2006a, AU 2006b, AU 2006c) that there is a need to develop and use African languages in education, public administration (governance) and other areas of development along with English, French, Portuguese, etc., the official languages, as partner languages. The strength of this position is predicated on the premise that the rural population of Africa is characterised by poverty which stems from ignorance and illiteracy. 'Ignorance is a disease which only knowledge can cure' (Chumbow 1999). In the present age of information and technological development, illiteracy is the greatest obstacle to national development because it reinforces ignorance by limiting access to scientific and technological knowledge as well as general and technological know-how. The effective mobilisation of the masses of the rural population for national development 
so that they can become trained, skilled, knowledgeable and effective agents of change in the national development enterprise requires the democratisation of access to knowledge not in a foreign language but in a language or languages the people know best: an African language (Chumbow 2005).

What this means is that in nation building, the national development enterprise, to be effective, requires that the languages of the nation are developed, revitalised, revalorised and instrumentalized to assume development-related functions as language of education and language of communication in the economic sphere, etc. The Language Plan of Action for Africa (AU 2006a) and The Second Decade of Education in Africa 20062015 (AU 2006c) are two documents which evidence the commitment of the African Union (at the policy level) to ensure for African countries, development, based on linguistic pluralism.

In the implementation of this policy, many African countries experience difficulties some at the conceptual level and others, at the level of implementation. Studies abound dealing with such issues. These difficulties are of two types:

i) Practical Problems such as inadequacy of resources (trained teachers, textbooks and language materials), language teaching methodology, class size and numbers etc.

ii) Ideological Issues such as (preconceived) ideas and beliefs that pertain to power structure, ethnicity, multilingualism, and economic and social transformation.

Ideological issues have to do with the will. Hence ideological commitment and resolve for positive engagement can transform apparently daunting obstacles into mere challenges for which solutions are possible. The English adage 'where there is a will there is a way' is quite relevant here.

The most pervasive ideological issues affecting the directionality of language policy have to do with belief and attitudes towards diversity, multilingualism, pluralism and power in relation to social and economic development. In fact, most of the pragmatic polarisation and differences in policy have to do with differences on how to mediate diversity in relation to social, economic and political demands of power and development.

One of the most daunting challenges to the enterprise of national development is the very fact of linguistic and cultural diversity which makes the cost of multicultural development in a pluralistic ideology relatively high. The arguments in favour of multilingual and multicultural development of nations stem from the arguments in favour of the conservation of linguistic and cultural diversity to which we will now turn. 


\section{Linguistic Diversity and Pluralism}

There is a need to understand and underscore facts of linguistic diversity so as to treat them as facts or incontrovertible reality and distinguish these from positions and attitudes towards these facts. This will also be useful in understanding why despite the apparent difficulties posed by multilingualism in the enterprise of national development, the dominant ideological position is in favour of development anchored on linguistic and cultural pluralism.

\section{Universals of Linguistic Diversity}

Research has established certain facts about diversity in general and linguistic diversity in particular that are generally assumed as axiomatic in any discourse in sociolinguistics and language planning some of which are summarised here.

- Bio-diversity is a normal situation in nature and has advantages in that it helps to sustain and maintain the stability and the equilibrium of the world ecological systems (UNESCO 2005).

- Nations have pledged to safeguard and ensure the survival of biodiversity through commitment to sustainable development. (Rio Conference on the Environment).

- It has been shown that there is a co-relation between bio-diversity and linguistic and cultural diversity. Most countries with a high incidence of biodiversity also have a high level of linguistic diversity (Harmon and Maffi 2002; UNESCO 2003b).

- The same arguments in favour of bio-diversity therefore motivate and justify interest in and commitment to the sustenance of linguistic and cultural diversity. It is argued that the maintenance of linguistic and cultural diversity is as important to world cultural and linguistic equilibrium as bio-diversity (Harmon and Maffi op cit., and UNESCO 2003).

- Multilingualism is normal and monolingualism is exceptional. Most countries of the world are multilingual and even the few putatively monolingual countries of Europe are increasingly becoming multilingual and multicultural as a result of the mobility and migration factors characteristic of the phenomenon of globalisation.

- Africa is the most linguistically diversified continent with more than 2086 languages of the over 6600 languages of the world. As earlier noted, all African countries are multilingual in varying degrees; from three languages in Rwanda and Burundi to over 450 in Nigeria (Ethnologue 2005). 
- Multilingualism in Africa is paralleled by multi-ethnicity in that the multilingual nations are characterised by multi-ethnicity. To attack multilingualism is to attack ethnicity to which members of the ethnic group are emotionally attached.

- Language and culture are intimately related because language is a vector or carrier of culture. Language is the means by which people who belong to a common cultural community, express their belonging to that community. The loss of one language means a loss of part of the national cultural treasure.

- Multilingualism in the African context quite often implies multiculturalism or a plurality of cultures. However, because of the phenomenon of culture permeability (Chumbow 2005a), there are instances where there is not a one-to-one correlation between language and culture, thereby establishing the facts of bilingualism and bi-culturalism at the level of the individual.

\section{Linguistic Diversity and Ideology}

Recent scholarship on linguistic diversity and multilingualism has been focused on language endangerment and language maintenance. Languages that are functionally vibrant and full of vitality today may become endangered by losing their vitality and go through varying phases of attrition resulting in language loss or language death. To prevent endangered languages from dying, appropriate measures must be taken to ensure their maintenance by way of revitalisation, i.e., the process of re-enforcing their vitality (UNESCO 2003a).

Two conflicting positions arise with respect to linguistic diversity and language maintenance which we characterise below:

- Cultural Assimilation: This is an ideology which favours the assimilation of minority languages and cultures by a majority dominant language and culture. Cultural assimilation is a process whose finality (within the context of a hidden or open agenda), is the loss or death of the minority languages and cultures, usually within the space of three generations.

Cultural assimilation may be conscious and planned and therefore ideological. It may be unconscious and unplanned in which case it cannot be said to be ideological. Cultural assimilation whether ideological or not, is the result of the unfavourable balance of power against the minority language and culture. The dominant language and culture usually assimilate the weaker language where dominance is determined by such factors as the prestige status of the language, the 
number of valorising functions (economically viable domains in which the language is used), etc.

From the ideological perspective, cultural assimilation may be and is often used as an instrument of power to ensure the hegemonic domination of a cultural group by another or as an instrument to counter linguistic diversity and multiculturalism.

Whereas cultural assimilation as an instrument of power may be dismissed as an agency to impose cultural and linguistic imperialism, the instrumentalization of cultural assimilation to counter cultural and linguistic diversity is rationalised by the assertion that multilingualism and multiculturalism are sources of socio-economic inequalities. It is reasoned that the assimilation of cultural minorities is doing them a favour because they now can join the majority group and cease to be stigmatised and disadvantaged as a minority group. Thus, ideologically, assimilation is the instrument by which multilingual and multicultural communities can become monolingual and mono-cultural voluntarily or involuntarily.

- Cultural Pluralism: This is an ideology which seeks to maintain and develop each linguistic and cultural heritage within the nation-state. Such an ideology naturally favours linguistic diversity, multilingualism and the pluralism of cultures.

\section{Arguments in Favour of Linguistic Diversity and Pluralism}

Justification for cultural pluralism comes first from the incontrovertible facts of linguistic and cultural diversity discussed above. There are, however, independent arguments in favour of ensuring the maintenance of each existing language and culture within the nation-state as opposed to eliminating multilingualism and multiculturalism by the instrumentality of ideological cultural assimilation and linguicide or linguistic genocide.

- Multilingualism is the norm and monolingualism, the exception. Therefore any policy that seeks to counter multilingualism runs counter to nature (Chumbow 2008b).

- The languages of a nation are its natural resources on the same level as its cocoa, coffee, gold, diamond or petroleum Like all natural resources, they have to be exploited (planned, developed) and used for national development. However, if care is not taken to plan, multilingualism like its twin, multi-ethnicity, may become a source of tension and conflict within the nation-state (Chumbow 1987). 
- The co-existence of two or more languages is rarely in itself the cause of tension, conflict, disunity and war. On the contrary, historical evidence shows that it is economic, political and religious factors which cause conflicts, tensions and wars (Fishman 1986; Baker 2003). In other words, the so-called language and linguistic wars or conflicts (Calvert 1998) are ultimately caused by problems of social, economic and political power inequalities between linguistic communities, not by the languages per se. In other words they are caused by extra, supra and paralinguistic factors.

- Language is a historical heritage and is consequently a repository of the history of humanity. Language is the means of accessing knowledge, ideas and beliefs of the past. If one language disappears a world vision of mankind is lost and the world is the poorer for it (UNESCO $2003 \mathrm{a}$ ).

- Language is an element and a vector of culture. 'Every language is a monument to the culture that it vehicles' (Nettle and Romaine 2002:114). The loss of a language amounts to the loss of irreplaceable cultural monuments.

- Language is an intimate means of personal identity. Individuals are very often emotionally linked to their mother tongue to the extent that it is the means of expressing one's innermost thoughts and one's ego, personality and (ethnic) identity.

- Language is a right; a human right of the same level of importance as all other inalienable human rights. All languages have the right to be developed and used by those who speak them for their own development. All forms of linguistic discrimination should therefore be fought and countered (Skutnabb-Kangas and Phillipson 1995).

These and many other arguments have led UNESCO to take a position in favour of the conservation of linguistic and cultural diversity. To this effect, the year 2001 was declared the year of the mother tongue to focus on each and every language in its role as the mother tongue of some speakers. Before then, 8 September was declared world literacy day, with special attention to literacy in the mother tongue. The United Nations Decade of Literacy (20032012) was declared to advance the cause of the eradication of illiteracy (of the about one billion illiterates, most of whom are in Africa), and ensure the availability of knowledge in languages of the rural masses. The year 2008 was declared the international year of languages, again to show-case languages as indispensable factors of personal, community and national development. All of this constitutes advocacy for multilingual and multicultural pluralism in national development at the highest international level (UNESCO, UN). This position was reinforced at the continental level by the African 
Union's declaration of the year 2006 as the Year of African languages and extended to 2007. Many African nations are now grappling with implementation strategies to which the following sections should be relevant.

\section{Language Planning in the Public Sphere}

Given ethnolinguistic identity as an ideological foundation for pluralism within the nation-state, there is need for a model and a model is hereby conceived and presented that makes it possible for languages to be maximally utilised in the public sphere, such that each language community can conserve, preserve and maximise the development of its ethno-linguistic identity and ensure the optimal use of its language at some level(s) of the public sphere.

\section{The Tier Stratification Model}

Drawing from Jurgen Habermas's concept of the public sphere (Habermas 1965), we adopt and adapt the concept in the context of language planning for national development in a multilingual pluralistic nation-state as follows:

All languages of the nation-state belong to the public sphere. This underscores the tenet of pluralism and the need to ensure and guarantee a place in the sun for each ethno-linguistic community in a pluralistic national community.

All languages indigenous to the nation belong to and make maximal use of the private realm.

Foreign languages that do not have native speakers within the nationstate do not belong to the private realm but those that do, belong. The private realm is characterised essentially by the identity function of language as a mother tongue of those who acquire and use it as a first language.

Languages of the private realm can be and should be used in a wide variety of functions and domains beyond the basic identity function (for example, education, commerce, etc.) as will be shown below.

Some languages of the private realm along with exoglossic or foreign languages that may or may not belong to the private realms, are selected to constitute languages of the Public Realm. Languages of the public realm are languages which in addition to their basic identity function of the private realm are established to perform some function at one or more levels of administrative units of the state's governance machinery, such as language of local government councils, districts, divisions, provinces, (regions), states, and nation.

The public realm is stratified into as many tiers or levels as there are administrative units in the nation.

The Tier Stratification Model is represented in Figure 1. 
Fig. 1: Tier Stratification Model of Language Planning in the Public Sphere

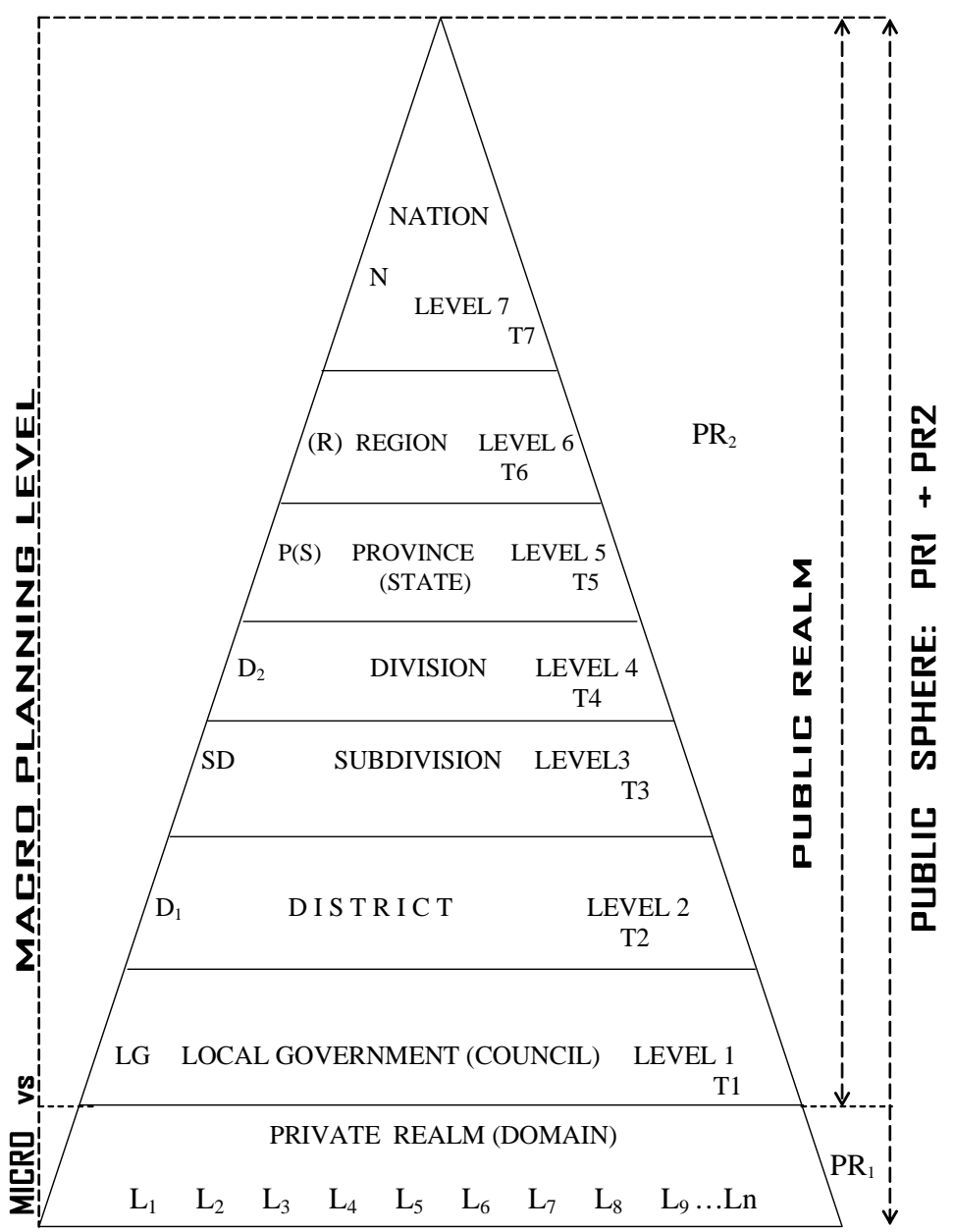

Key: L= Language; Ln= any number of Languages; $\mathrm{PR}_{1}=$ Public Realm; $\mathrm{T}=$ Tier. 
The number of languages to be selected for each tier of the public realm is not determined a priori. It depends on the linguistic reality of each situation. However, there is a need to strike a balance between considerations that seek to ensure that development information is available to a large number of people, and limiting the number of languages in order to lessen the burden for the public of the number of languages to be learned. That is why variants that seek to simplify this basic situation (as discussed below) are appropriate and reasonable where feasible. The pyramidal nature of the model underscores the fact that there are more languages at the base (the private realm) and these gradually decrease with each level of the public realm, so that at the apex which is the national level, one expects only a minimal number of languages (one to three).

\section{Functional Organisation of Elements of the Model}

It follows from the above that this model envisions the development and use of language in the public sphere in terms of a stratified pyramid whose base is the private realm and the equilateral sides, the public realm.

\section{The Private Realm}

From the language planning theory perspective, the private realm is the level at which micro-sociolinguistic planning is undertaken in that it is the level at which all languages of the nation are present as languages of the ethnolinguistic communities that make up the pluralistic national community.

At this level, languages manifest their existence, their vibrancy and their raison d'être as language and symbol of identity and element of culture par excellence of a dynamic (ethnic) community that has a right to its language and culture and more importantly, a right to access and disseminate information, knowledge and technology in the language. Each language community has not only the right but also the responsibility of ensuring the intergenerational transmission of the language and culture to the future generations that will inherit and retransmit the language. Individual members of each linguistic community ensure the use of the language in all areas of community interest by organising development projects and cultural manifestations, etc., including school and adult literacy programmes in the community language or mother tongue. This is the sense in which this realm is called private. It is private in that all language-related and language-dependent aspects of community interest are catered for primarily (but not solely) at this level.

Private (realm) does not mean unimportant (realm) as should be obvious from the above. Rather, the private realm is functionally the most fundamental, 
as the base or foundation on which the rest of the national edifice is to be constructed. Just like there is no national community without the ethnolinguistico-cultural communities that make up the nation, it is an aberration to talk of official language(s) or national language(s) without the community languages which have a vibrant and dynamic existence as the language of socio-cultural interaction as well as the language of economic and political development of the various communities at the base. Worse still, it is the greatest form of marginalisation not to ensure that all the measures putatively taken by government for the developmental needs of the citizens, for example, with respect to the millennium development goals in the areas of education, health care delivery, agriculture and food security, environmental and biodiversity conservation, poverty reduction etc., are available to the people in a language they best understand, the language of the ethno-linguistic community. The provision here is that micro-level language planning is to be undertaken as a partnership with the elites of each language community, to develop the language for use in as many domains and functions as possible. Concretely, development and use of the language may involve inter alia revitalization, revalorization, instrumentalization and intellectualization of the language where necessary (Alexander 2005 and Chumbow 2007). How are the languages in the Private Realm (PR1) to be organised and structured, since except for the foreign languages, all languages belong to this realm? From the language planning perspective, these languages can be organised and clustered in terms of any one of the superordinate administrative units of the public realm (languages of the local government area, council or municipality, languages of the district or subdivision, languages of the division or province, etc.). It is, of course, understood that languages of any tier or level of administrative unit will reflect the hierarchical order embodied in the tier stratification. Thus, for instance, languages of a province will be presented by division and those of each division will be clustered into sub-divisions which in turn will be sub-divided into local government areas or councils each of which finally, indicates the community languages attested in its local domain. This hierarchical stratification can be presented in the form of a branching tree diagram similar to those realisable for historical reconstructions reflecting genetic relationships between various languages at different generational levels.

The model further prescribes that the complete identity of each language in the private realm be chain-commanded from the public realm above. Thus, the language Mankon will be described as a (grassfield Bantu) language spoken in the Bamenda II council/local government area (T1) of the Bamenda 
Subdivision (T3) in the Mezam Division (T4) of the North West Province (T5) of Cameroon (T7). Note that no district (T2) and Region (T6) are relevant to the description. The chain of command in this process of identification underscores the fact that these administrative units have the privilege of counting the particular language as one of their treasures (in the same way that they would value lakes, rivers, mountains, etc in their area of jurisdiction).

In the same vein, the language and its speakers can claim and assert their territorial belonging to the public realm and to a fatherland. The superordinate chain of command also means that the various tiers and levels have authority over the language and the language community but also responsibility for the development (revalorization and instrumentalization) of the language to assume old and new functions in national development.

\section{Public Realm}

This is the realm in which selected languages of the private realm and other international languages resulting from the colonial heritage are assigned functions to serve the public as language of official business and governance in some identified administrative unit. In the public realm, the administrative units are ordered or stratified into levels or tiers, from the smallest (council) to the largest which is the state or the nation. The number of tiers in the public realm is equal to the number of state-recognised administrative units. An important assumption in this conception of the language use in the public realm is that good governance in a pluralistic state presupposes decentralisation in consonance with boundaries of natural affinities determined by cultural bonds and /or geographical contiguity. Thus for the public good and in the interest of bringing government and governance closer to the people, there is a need for some languages of a particular decentralised unit of administration to be objectively selected to serve (in conjunction with the national language(s)), the purpose of administration, governance and development at that level without any prejudice to the community languages of the unit, which must continue to serve individual and community interest in relation to the interest of the public at the level of the wider administrative unit.

Language planning at the public realm is at the macro-planning level. The cardinal language planning processes in the African context which, as mentioned above, consist of revitalisation, revalorization, instrumentalization and intellectualization of languages are applicable in the development and use of language in the public realm but with the realisation that there is a need here to plan for a bigger and more complex unit which aggregates, at least, 
some of the relatively homogeneous language communities of the private realm at the micro-planning level.

\section{Public Sphere}

The public sphere in this paradigm is the aggregation of the private and public realms. The languages of the private realm constitute the foundation or base on which the languages of the public realm are firmly grounded. This underscores the fact that the discourse of national development in the public realm must take into consideration the multilingual and multicultural realities at the base or private realm. Put differently, in the public sphere or national territory, policy for the mega language(s) that function as official languages, should be inextricably linked (by policy) to the reality of the ethnolinguistic diversity at the base. Ultimately there should be a bidirectional flow of information from the top to the base and vice versa, or from the official and national language(s) to and from the community languages.

In this way, the products of development will be shared by the national community thus eliminating the present state of affairs characterised by the marginalisation of the rural communities whose community languages are presently not involved in the national development discourse. The public sphere in relation to tier stratification is made up of the tiers of recognised administrative units plus one (the additional tier being the fundamental tier of the private realm).

\section{Variations in the Tier Stratification Model}

Various forms of the model may be envisaged as dictated by the interest and will of the nation-state. Given the characteristics of the private realm as the fundamental zone where all languages are attested and perform their primary function of language of ethnic and cultural identity, etc. it follows that no modifications can reasonably be effected here without doing violence to the status and function of the private realm. Thus, any modifications can only be conceptualised at the level of the public realm.

\section{National Language Stratification}

This is a variant where the public realm is conceptualised to use only one (African) national language for all the administrative units of the public realm and in all the functions and domains (along with a partner language, i.e. a foreign language serving as official language and language of international discourse or language of globalisation). This is illustrated in Figure 2. 
Fig. 2: One (National) Language Stratification (Modified Versions of the Tier Stratification Model)

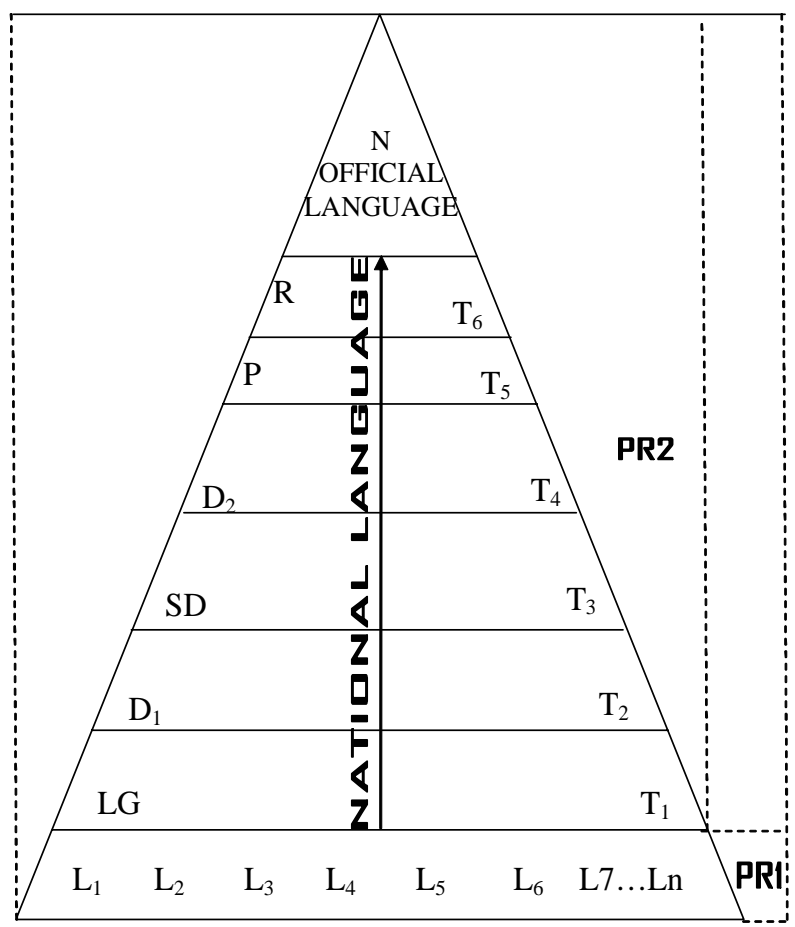

A typical example is the situation in Tanzania where Kiswahili is the national language used in all administrative units and all functions of the public realm with about 120 languages in the private realm and English as official language. The reservation with respect to the Tanzanian example is that, contrary to what is prescribed in this model, the adoption of a national language has led to the neglect of the community languages (Batibo1992, 2005; Mkude 2001; Rubanza 2002).

Two or More National Languages Stratification

In this variant the nation or public sphere conceives two or more (but a limited number of languages) to be used in the public realm in prescribed zones or regions of the country. Figure 3 represents this variant. 
Fig. 3: Five Languages Stratification

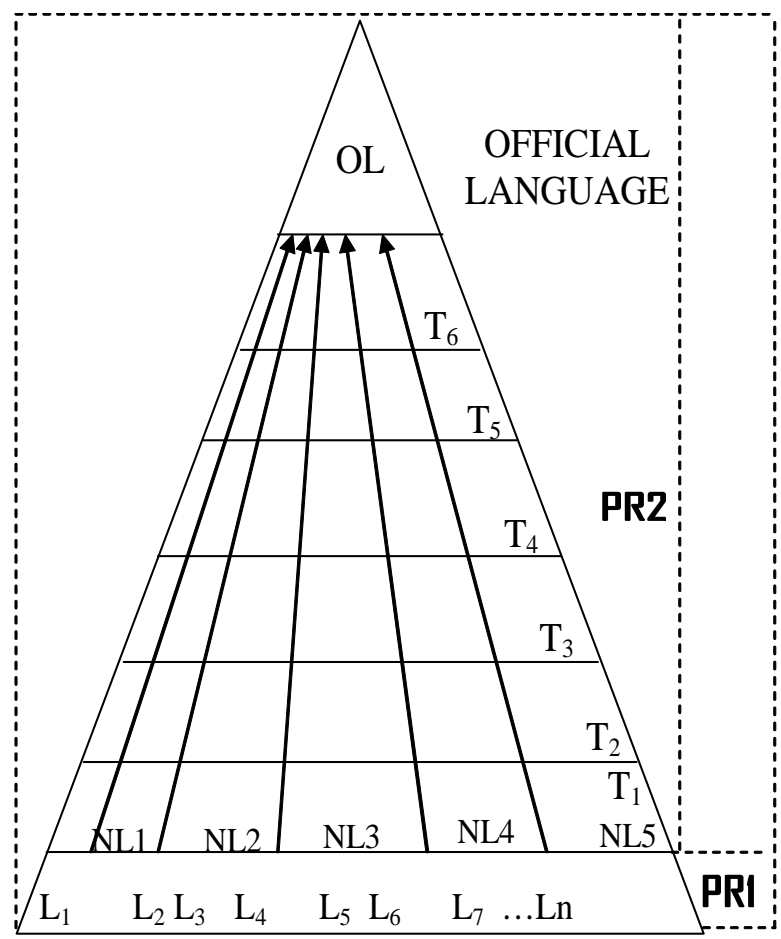

Nigeria would be a good candidate for such a stratification, where Hausa, Yoruba, Igbo and Fulfulde spoken by over fifteen million people each, can safely be declared the language of education and governance of the public realm in several states along with English, the official language, while each of the about 450 languages are used at the level of the private realm.

\section{Mediation of Linguistic Dominance and Tension}

Ethnolinguistic pluralism although important as it is as an ideal for nation building, has embedded in it germs of social tension resulting from linguistic dominance and marginalisation. Majority languages tend to be more dominant than minority languages as a result of their prestige status and the economically important functions they are called upon to play. This may lead to polarisation and social conflict of ethnolinguistic communities as a result of problems of non-linguistic origin, with the law of the jungle or survival of 
the fittest playing against the minority language and minority linguistic groups which may then succumb to assimilation. The result, of course, would be the loss of the language and linguistic identity, and a cruel blow to the lofty ideal of linguistic pluralism. The key to the survival of any language in a multilingual situation is its vitality which is determined by a network of micro and macro-linguistic (maintenance) variables that ensure that the language is alive and strong enough to withstand the vicissitudes of threats from other languages in contact. The acquisition or allocation of these factors determines the dominance configuration of the languages in contact and the extent of their vitality and therefore the chances of their survival in the face of threats and endangerment.

Since, in any multilingual and multicultural pluralistic state, dominance prevails as determined by a conjunction of vitality and status-conferring variables of a social, economic and political nature, we submit that Language Planning (LP) has the duty and responsibility of mediating dominance, by way of redistribution of the variables so that all the languages have at least the minimum required for their vitality and survival. The point being made here is that without intervention and a judicious mediation of the variables, we involuntarily (or voluntarily?) ordain the slow death of some of the languages ultimately. This is so because in any language contact situation, the default situation is the law of the jungle or the survival of the dominant (and powerful) languages in the power-configuration and the concomitant progressive weakening, attrition or loss of disempowered minority languages.

\section{Functional Complementarities and Mediation}

The principle of complementarities of functions proposed and motivated in this section pertains to the domains in which minority languages are used in relation to the domains of the majority or dominant language.

The normal distribution of power between majority and minority languages is not dependent on the intrinsic value of the languages concerned but on historical accidents, of military, political or economic power. Thus, the balance of power in favour of dominant official languages in the African context is due to the unfortunate circumstances of imperialism, economic rape, etc., in the era of colonisation. It may also be attributed to a conspiracy ignited by the forces of globalisation in collusion with the local African ruling class (Mazrui 1997) or by the survival instinct of the African elite class struggling to protect its monopoly in the use of the foreign languages as a source of economic and political power that excludes the masses (Myers Scotton 1993). Similarly, social, economic, ethno-cultural and political factors of dominance explain the ascendancy of the other dominant mega African languages. 
Commitment to linguistic diversity means acceptance of ethno-linguistic pluralism as a fundamental element in the paradigm of development for African nations. This requires the promotion of peaceful co-existence of ethnolinguistic groups of people in a pluralistic society where plurality does not entail replacement of one language by another but a recognition of the functional complementarities of all languages in a relation characterised not by mutual antagonisms but by mutual support. Given its importance, the principle is defined as follows:

The principle of functional complementarities (PFC) requires that at the level of status planning (or policy formulation), all languages of the nation-state should be ascribed their identity function (the primary function) and be allocated some other valorising functions (education/literacy, media, public administration, parliament, business/commerce, etc.) necessary to assure the vitality and maintenance of the language and its contribution to the national development enterprise in the private and public realms.

Valorising Functions are those that procure economic, social and political advantages and thereby contribute to raising the status of the language.

What is the motivation of the principle of functional complementarities and what is it intended to achieve?

- Firstly, the PFC is congruent with the objectives of pluralism and the need to develop multilingual and multicultural societies where all ethnolinguistic identities are nurtured, preserved and harnessed for national development.

- Secondly, it seeks to empower minority languages which have generally been disempowered by being left with only the identity function to boast of, leading to a situation where users choose to go straight for the dominant language of power, which guarantees economic advantages and social amenities, leading to the abandonment, endangerment and consequent shift of the minority language. In South Africa, for instance, parents and pupils reject mother tongue facilities because the mother tongue in the bilingual education system does not lead to any valued functions, unlike English, and it is therefore considered a waste of time (Stroud 2001; Alexander 2001, 2005; Kamuangamalu 2003).

- Thirdly, commitment to the PFC requires that languages share some functions, and that their users be supportive of each other and see each other as members of a team whose goal is attainment of the ideal of national development. The principle of complementarities commits all linguistic communities to some sort of vicarious responsibility for their common endeavours for national development. 
- Fourthly, redistribution and sharing of valorising functions by this principle reinforces the vitality of all languages including minority languages and thereby guarantees their survival and stability.

\section{Attitude Engineering}

In the implementation of the PFC and other principles geared towards ensuring harmony in the development of the various ethnolinguistic communities in a pluralistic nation-state, the most formidable obstacle to the endeavour is the negative attitude of citizens towards the other language or towards their own language (in preference to a foreign official language).

Negative attitudes tend to heighten vulnerability when confronted by difficulties or pressure from another language (Gardner 1985). In the case of negative attitudes towards one's own language, one is ready to give in at the least difficulty. Similarly, if the negative attitude is towards another language, one is predisposed to be aggressive with the slightest excuse. Those with a positive attitude, on the other hand, tend to resist pressure and invoke linguistic human rights and minority rights, (etc.) to get results in favour of their language, or any language perceived to be the object of victimisation.

To deal with this syndrome, we propose the principle of attitude engineering (PAE).

- By attitude engineering we mean the systematic use of sociolinguistic and psycholinguistic knowledge, principles and techniques to determine attitudes of government and the speakers of various languages in a language contact situation and the use of the findings as input for the design and implementation of a programme to effect polarisation of attitudes in the direction of a desired policy outcome.

What is the rationale for the technology of attitude engineering proposed here?

- The ability for a language to resist domination pressure and adopt mechanisms to appropriate and consolidate the use of existing domains and penetrate new domains and acquire valorising functions etc., as proposed above, depends on the attitude of its users.

- A positive attitude resulting from the application of the PAE and dynamism in favour of the maintenance of the language will guarantee intergenerational transmission of the language to children and ensure that the linguistic community maximises the possible absolute numbers of speakers and the proportion of speakers of the language within the population. 
- The attitude and socio-economic dynamism of speakers of a language often contribute to the acquisition of that language as a second language by others outside the linguistic community, thus contributing to the vehicularity of their language.

- With positive attitudes, speakers can constitute Language Planning Committees and mobilise the elites of the linguistic community to lobby for government and institutional support, ensure the production of language and literacy materials and undertake relevant documentation.

- With a positive attitude, members of a linguistic community can fortify and re-dynamise their own attitudes, leading to positive actions and concrete achievements in the maintenance of the language's vitality. The process of mutual reinforcement between attitude and results produces a multiplier effect which maximizes and optimises opportunities.

Another dimension of the PAE is to verify not only the attitude of linguistic minorities but also government's attitude so as to usher in macro-level changes and actions in favour of linguistic minorities. A relevant question in this respect among others is whether there is a policy instrument in favour of the development and use of minority languages in key domains which linguistic communities can use as warrants for their initiatives and as a basis for countering resistance from dominant groups.

A fourth dimension is that attitude engineering as a macro level psychosocial technological activity is intended to bring about the often vaunted but very elusive 'change of mind set'. It is a dilemma of contradictions that Africa and its people are endowed with natural resources of considerable variety, quantity and quality, but remain eternally poor. Scholars who examine this and similar issues have come to the conclusion that what Africans need is a 'change of mindset'.

In a keynote address at a conference on 'Language and development in Southern Africa', Alexander (2001) having reviewed the vexing issue of negative attitudes to the acceptance, adoption and commitment to mother tongue in education policy, which he like Ngugi wa Thiong'o (1995) attributes in part, to the colonial mentality which sees English, the language of imperialism as the only medium for intellectual and academic discourse, laments this state of affairs in the following question:

How can we transform the climate of opinion so that we can shift the colonial minds from the groundless belief that only knowledge which is packaged in the languages of the colonial conquerors is worthwhile knowledge? 
He proposes that beyond awareness campaigns, 'structured interventions that are calculated to demonstrate the economic power and the status-conferring potential of African languages' are needed.

Observations on the need for a change of mindset in Africa characterise much of the discourse of social sciences research generated or published by CODESRIA.

It is therefore clear that the concept of change of mindset putatively has some validity. However, it is not clear what mindset change means, or what it entails. It is as yet only a construct that must be operationalized. There is a need for theory of mindset change. It is however, self evident that a change of attitude is an indicator of a mindset change in that the change of mind set inevitable has to go through or result in attitude change resulting from attitude engineering. Ultimately, attitude engineering principles can be generalised to take care of such intractable issues as HIV/AIDS campaigns, etc. The concept and process of Attitude Engineering sketched above has the potential of satisfying the need for a model that can organise a structured set of actions and activities that will result in a mind set shift manifested in attitude change in any area where attitudes are relevant and important. A discussion of these issues is beyond the scope of this paper. For the interested reader these issues are sketched in Chumbow (2008a).

\section{Conclusion}

This paper seeks to examine and elucidate the problematic of pluralism as an ideological basis for nationalism, nationhood and national development in Africa faced with the daunting challenge of linguistic diversity and ethnolinguistic identities within the nation-state. A study of the facts of multilingualism and multiculturalism provides the background for a framework for language planning in the public sphere. The Tier Stratification Model provides for the private realm where all community languages of ethnolinguistic communities are catered for at the micro-planning level and the public realm where the language needs of administrative units of the public domain are managed at the macro-planning level. The model seeks to capture the dialectical and dynamic relation that exists between the languages at the private and public realms. Given the potential problem of dominance and tension in situations of language contact and the need for a harmonic relationship of symbiosis in a pluralistic state, the Principles of Functional Complementarities and of Attitude Engineering are proposed, motivated and rationalised as relevant factors in the mediation of the relation between languages of the private and public realms, in an ideal language planning model that seeks to enhance national identity while maintaining pluralism and ethnolinguistic diversity. 


\section{References}

Alexander, N., 2001, 'Key Issues in language policy for Southern Africa’, in Trewby, Richard and Sandra Fitchat, eds., 2001.

Alexander, N., ed., 2005, The Intellectualisation of African Languages. The African Academy of Languages and the Implementation of the Language Plan of Action for Africa, Cape Town, PRAESA.

AU, 2006a, The Charter of the African Cultural Renaissance, Addis Ababa, The African Union.

AU, 2006b, Language Plan of Action for African Development, Addis Ababa,

The African Union.

AU, 2006c, Second Decade of Education in Africa 20006-2015, Addis Ababa, The African Union.

Baker, C., 2003, Bilingual Education, Multilingual Matters, Clarendon, Buffalo, Toronto.

Bamgbose, A., 1991, Language and the Nation: The Language Question in Subsaharan Africa, Edinburgh, Edinburgh University Press.

Bamgbose, A., 2005, 'Mission and Vision of the African Academy of Languages', in Alexander, N., ed., 2005.

Batibo, H., 1992, 'The Fate of Ethnic Languages in Tanzania', in Brenzinger, M., ed., Language Death: Factual and Theoretical Explorations with Special Reference to East Africa, Berlin \& New York, Mouton de Gruyter.

Batibo, H., 2005, Language and Death in Africa. Causes, Consequences and Challenges. Multilingual Matters, Clarendon, Buffalo, Toronto.

Calvet, L.J., 1998, La guerre des langues et les politiques linguistiques, Paris, Hachette.

Chumbow, B.S., 1987, 'Language Planning Model for Africa', Journal of West African Languages, vol. 2, 1987.

Chumbow, B.S., 1990, 'The Mother Tongue in the Nigerian Language Policy', in Emananjo, Nolue, ed., Minority Languages and Education in Nigeria, Agbor, Nigeria, 1990.

Chumbow, B.S., 1999, 'Thematic Glossaries in Language Development’, in Birgit Smeija, ed., Maintaining Contacts through Language, Berlin, John Benjamins and Sons.

Chumbow, B.S., 2005, 'The language Question in National Development in Africa', in Thandika Mkandiware, ed., African Intellectuals: Rethinking Gender, Language and Politics in National Development, CODESRIA, Dakar.

Chumbow, B.S., 2005a, 'Language, Culture and National Development', Paper Commissioned by the African Union, The Conference of African Ministers of Culture, Nairobi.

Chumbow, B.S., 2007, 'The African Academy of Languages and the Continental Language Development Programme', A keynote Paper at the Conference on Nordic Contributions to African Linguistics. University of Goteborg, Sweden April, 2007. To appear in the Proceedings of the Conference edited by Karsten Legere. 
Chumbow, B.S., 2008a, 'Vehicular Cross Border Languages and Endangerment of Minority Languages. Mediating a Symbiotic Functional Relationship’, in Bulletin of the African Academy of Languages (ACALAN), No. 03 December 2008, pp. 26-36.

Chumbow, B.S., 2008b, 'La politique linguistique de l’Académie Africaine des langues et la diversité linguistique’, Communication au colloque Internationale sur la Diversité linguistique dans les Universités de la francophonie, Yaoundé 2008.

Chumbow, B.S. and Tamanji, P., 1997, 'Linguistic Identity across the Border of the Cameroon Triangle’, in Prah, Kwesi, ed., Between Distinction and Extinction: Harmonisation and Standardisation of African Languages, Johannesburg, Witwatersrand University Press, 53-73.

Crystal, D., 2000, Language Death, Cambridge: Cambridge University Press.

Fishman, J., 1968, 'Language Maintenance and Language Shift as a Field of Inquiry', Linguistics 9: 32-70.

Gardner, R.C., 1985, Social Psychology and Second Language Learning: The Role of Attitudes and Motivation, London, Edward Arnold.

Harmon, D. and Maffi, L., 2002, ‘Are Linguistic and Biological Diversity Linked?’, Conservation Biology in Practice 3,1.

Habermas, J., 1965, Structural Transformation of the Public Sphere: An Inquiry into a Category of Bourgeoisie Society, Frankfurt.

Kamuangamalu, N., 2003, 'Globalisation of English and Language Maintenance and Shift in South Africa', International Journal of the Sociology of Language, 164, 65-81.

Mazrui, A., 1997, 'The World Bank, the Language Question and the Future of African Education', Race \& Class 38 (30) 35-48.

Mkude, D., 2001, 'Minority Languages vs. Kiswahili in Tanzania: A Painful Dilemma', in Trewby, Richard and Sandra Fithat, eds., 59-167.

Myers S.C., 1993, 'Elite Closure as a Powerful Language Strategy: the African Case', International Journal of the Sociology of Language, 103,149-163.

Nettle, D. and Romaine, S., 2000, Vanishing Voices. Extinction of the World's Languages, Oxford, Oxford University Press.

Ngugi, W.T., 1995, Decolonising the Mind: The Politics of Language in African Literature, London, Heinemann.

Rubanza, Y., 2002, 'Competition through English: The Failure of the Tanzanian Language Policy’, in Prah, Kwesi, ed., Rehabilitating African Languages, Cape Town, CASAS.

Skutnabb, K.T. and Phillipson, R. eds., 1995, Linguistic Human Rights. Overcoming Linguistic Discrimination, Berlin, Mouton De Gruyter.

Stroud, C., 2001, 'African Mother-tongue Programmes and the Politics of Language:

Linguistic Citizenship versus Linguistic Human Rights', Journal of Multilingual and Multicultural Development, Vol. 22, no. 4, 339-355.

Trewby, R. and Fitchat, S. eds., 2001, Language and Development in Southern Africa: Making the Right Choices, Windhoek, Gamsberg, Macmillan. 
UNESCO, 1953, The Use of Vernacular Languages in Education, Paris, UNESCO Press.

UNESCO, 2003a, Education in a Multilingual World, Paris, UNESCO Position Document.

UNESCO, 2003b, Ad hoc Expert Group on Endangered Languages. Language Vitality and Endangerment. Ms. Paris, UNESCO.

UNESCO, 2003c, 'Partager un monde de différence. La diversité linguistique, culturelle et biologique de la terre’, UNESCO TERRALINGUA, Fond Mondial pour la Nature. 
